\title{
ESTUDO DE MINERAIS, MINÉRIOS E MATERIAIS DE MANGANÊS
}

R.Hypolito ${ }^{1}$

J.V.Valarelli ${ }^{1}$

S.M.Netto ${ }^{2}$

M.C.Salvador ${ }^{2}$

S.A.Andrade ${ }^{1}$

M.Balbino ${ }^{1}$

R.S.Cardenete ${ }^{1}$

M.L.da Silva ${ }^{1}$

Têm sido realizadas sínteses de óxidos e óxidos hidratadados de manganês, análogos aos minerais constituintes dos minérios supérgenos, que permitem: determinaçáo dos parâmetros termodinâmicos e estruturais; estudo de transformaçóes mineralógicas que ocorrem no meio natural; estabelecimento de mecanismos de formação (gênese) e de associações em equilíbrio (paragênese).

Paralelamente alguns minérios naturais e outros materiais manganesíferos têm sido objeto de tratamento hidrometalúrgico para sua melhoria e valorização.

\section{SÍNTESE DE MINERAIS}

1. Criptomelana, $\mathrm{KMn}_{8} \mathrm{O}_{16}$ - Foram preparados compostos análogos à criptomelana, ora pela oxidação de sais de manganês (II) com o $\mathrm{O}_{2}$ (HYPOLITO et al., 1982) ora pela redução de $\mathrm{MnO}^{4-}$ com $\mathrm{HCl}$ ou $\mathrm{Zn}^{+2} / \mathrm{H}^{+}$(HYPOLITO et al., 1982).

\footnotetext{
Departamento de Mineralogia e Petrologia, Instituto de Geociências/USP, São Paulo.

2 Pós-graduação, Instituto de Geociências/USP, São Paulo.
} 
Estas sínteses permitiriam não só que se desenvolvessem novos métodos de obtenção, como também que se estudasse a influência da incorporação de íons estranhos na estrutura, de $\mathrm{pH}$ de síntese, tempo de digestâo no grau de cristalinidade e temperatura de síntese.

Foi a partir desses métodos de síntese que se estabeleceu um dos mecanismos de formação de criptomelana no meio natural e que se constatou notável correlação entre $\mathrm{Mn}^{+4}, \mathrm{Mn}^{+3} \mathrm{e} \mathrm{K}^{+}$na composição química desse mineral (HYPOLITO, 1980).

Um dos métodos propostos possibilitou ainda a determinação de importantes parâmetros termodinâmicos, sendo um deles a Energia Livre de Gibbs de Formação desse minerais (HYPOLITO et al., 1989). Provou-se que essa energia livre é funçåo linear do teor de $\mathrm{MnO}_{2}$ segundo a expressão:

$$
\Delta \mathrm{G}_{\mathrm{f}, 298}=70,34 \mathrm{n}_{\mathrm{MnO}_{2}}{ }^{-5118,60 \mathrm{KJ} \cdot \mathrm{mol}^{-1}}
$$

Estes dados possibilitaram a construção de diagrama de equilíbrio de $\mathrm{pH}=\mathrm{f}$ (Eh) que elucidaram a gênese e paragênese dos principais óxidos supérgenos de manganês (HYPOLITO et al, 1980 e HYPOLITO et al., 1989).

2. Nsutita, $\boldsymbol{\gamma}-\mathrm{MnO}_{2}$ - A nsutita, da mesma forma que a criptomelana, é um óxido não estequiométrico $\mathrm{e}$, até o presente, não tem suas propriedades termodinâmicas determinadas com exatidão.

Em pH entre 0,50 e 3,00 tem-se conseguido síntese de produtos análogos a nsutita pela oxidação de $\left[\mathrm{Mn}\left(\mathrm{H}_{2} \mathrm{O}\right)_{6}\right]^{2+} \mathrm{com} \mathrm{O}_{2}$ e adição de solução alcalina.

Durante a síntese tem sido possível determinarem-se as variações de $\mathrm{pH}$ e $\mathrm{Eh}$ que, somados aos dados analíticos e mineralógicos, permitem a determinação de Energia livre de Gibbs desses produtos.

Trata-se de dados inéditos que permitirão que se estude com segurança a gênese e paragênese desse mineral.

3. Cobre, prata e oxônio criptomelana - Como muitos elementos metálicos são enriquecidos nos perfis lateríticos e acham-se associados a minerais manganesíferos, procurou-se sintetizar, por diferentes processos, criptomelana contendo cobre, prata e oxônio.

Os elementos metálicos funcionaram, seja como catalizadores das reaçōes, 
sorvidos pela criptomelana, ou como participantes da estrutura do $\mathrm{MnO}_{2}$ segundo a concentraçằo, $\mathrm{pH}$ e Eh.

Foram sintetizados, por diferentes métodos, os seguintes compostos com estrutura de criptomelana: $\mathrm{AgMn}_{8} \mathrm{O}_{16}, \mathrm{H}_{3} \mathrm{OMn}_{8} \mathrm{O}_{16}$ e $\mathrm{CuMn}_{8} \mathrm{O}_{16}$.

\section{TRATAMENTO DE MINÉRIOS}

1. O minério de manganês de Urucum, constituído essencialmente por criptomelana, hematita e argilominerais, com relação $\mathrm{Mn} / \mathrm{Fe}=3,5$ e $\mathrm{K}_{2} \mathrm{O}+\mathrm{Na}_{2} \mathrm{O}$ entre 4 e $5 \%$, foi submetido a tratamento para eliminação de álcalis e ferro.

Uma fração hausmanita, $\mathrm{Mn}_{3} \mathrm{O}_{4}$, foi obtida por tratamento térmico do minério com carvão seguido da moagem aquosa e separação magnética.

Os álcalis são recuperados na solução de moagem e o ferro na fração magnética sob a forma de magnetita $\left(\mathrm{Fe}_{3} \mathrm{O}_{4}\right)$ ou jacobsita $(\mathrm{Mn}, \mathrm{Fe})_{3} \mathrm{O}_{4}$.

A haussmannita submetida a refluxo nítrico transforma-se em nsutita, $\alpha$ $\mathrm{MnO}_{2}$, material nobre que graças às suas propriedades despolarizantes é empregado na fabricação de pilhas secas (VALARELLI et al., 1985).

2. Minério pirolusítico da regiâo de Sete Lagoas, MG, submetido a redução transforma-se em bixbyíta. Este, por refluxo nítrico em condições controladas transforma-se também em nsutita de qualidade eletrolítica.

\section{TRATAMENTO DE MATERIAIS MANGANESÍFEROS}

Material manganesífero subproduto de redução de permanganato de potássio, empregado na indústria farmacêutica e caracterizado como constituído por groutita de baixa cristalinidade e óxido-hidróxidos amorfos foram tratados com êxito.

Por filtração separa-se a sílica (diatomito) empregada no filtro prensa. Refluxo nítrico elimina o potássio presente, sendo recuperado como nitrato de alto valor como fertilizante.

No processo obtém-se nsutita também de qualidade eletrolítica (VALARELLI et al., 1986). 


\section{REFERÊNCIAS BIBLIOGRÁFICAS}

HYPOLTTO, R. (1980) Criptomelana-síntese e estabilidade. São Paulo, 160p. (Tese de LivreDocência - Instituto de Geociências/USP).

HYPOLITO, R.; GIOVANOLI, R.: VALARELLI, J.V.; SONOKI, N.T. (1982) Síntese de criptomelana. Boletim IG, 13:1-13.

HYPOLITO, R.; GIOVANOLI, R.; VALARELLI, J.V. (1982) Obtenção de criptomelana a partir de $\mathrm{Mn}^{+2}$ e outros minerais sintéticos de manganês. Anais da Academia brasileira de Ciências, 54(4):713-720.

HYPOLITO, R.; GIOVANOLI, R.; VALARELLI, J.V.; NETTO S.M.; ANDRADE, S. (1989) Cálculo da Energia Livre de Gibbs de Formação de criptomelana através de potenciais de óxido-redução. Anais da Academia brasileira de Ciências, 61(3):269-273.

HYPOLITO, R.; GIOVANOLI, R.; VALARELLI, J.V.; NETTO, S.M. (1989) Nouvelles données d'enthalpie libre de formation (Gf,298) des cryptomélanes synthétiques: consequences paragénétiques. Sciences Géologiques Bulletin, 41(1):55-62.

VALARELLI, J.V.; HYPOLITO, R.; OLIVEIRA, L.T. (1985) Processo de tratamento de minério de manganês à base de criptomelana e hematita. INPI, Patente $\mathrm{n}^{2} 85002128$.

VALARELLI, J.V.; HYPOLITO, R.; NETTO, S.M. (1986) Processo de tratamento de resíduo industrial, produto da redução de permanganato de potássio. INPI, Patente $\mathrm{n}^{2}$ 3801578 . 